Research Article

\title{
Preparation and Microwave Absorption Properties of Polyaniline and Magnetite Core-Shell-Structured Hybrid
}

\author{
Xuan Zhang (iD \\ Department of Chemical Engineering, Northwest University, China \\ Correspondence should be addressed to Xuan Zhang; zhangxuan0904@stumail.nwu.edu.cn
}

Received 29 June 2018; Revised 7 August 2018; Accepted 9 August 2018; Published 24 October 2018

Academic Editor: Zhiyuan Xiong

Copyright @ 2018 Xuan Zhang. This is an open access article distributed under the Creative Commons Attribution License, which permits unrestricted use, distribution, and reproduction in any medium, provided the original work is properly cited.

\begin{abstract}
In this study, polyaniline and $\mathrm{Fe}_{3} \mathrm{O}_{4}\left(\mathrm{PAN} @ \mathrm{Fe}_{3} \mathrm{O}_{4}\right)$ hybrids are fabricated and their microwave absorption property is studied. PAN@Fe $\mathrm{O}_{4}$ hybrids are fabricated by the in situ aniline polymerization at spherical of $\mathrm{Fe}_{3} \mathrm{O}_{4}$ which is prepared by the solvothermal process. Fourier-transform infrared spectrophotometer (FTIR), X-ray diffraction (XRD), and X-ray photoelectron spectroscopy (XPS) are applied to confirm the composition of the fabricated PAN@ $\mathrm{Fe}_{3} \mathrm{O}_{4}$ hybrids. The morphologies of PAN@Fe $\mathrm{O}_{4}$ hybrids are studied by scanning electron microscope (SEM) and transmission electron microscopy (TEM). The content of polyaniline in the PAN@ $\mathrm{Fe}_{3} \mathrm{O}_{4}$ hybrids is calculated by thermogravimetric analysis (TGA). The magnetic properties of PAN@ $\mathrm{Fe}_{3} \mathrm{O}_{4}$ hybrids are characterized by vibrating sample magnetometer (VSM). The microwave absorption property of $\mathrm{PAN} @ \mathrm{Fe}_{3} \mathrm{O}_{4}$ hybrids are measured on a vector network analyzer. The research show that the microwave absorptions property of the obtained PAN@ $\mathrm{Fe}_{3} \mathrm{O}_{4}$ hybrids can be adjusted by controlling the in situ aniline polymerization at spherical of $\mathrm{Fe}_{3} \mathrm{O}_{4}$.
\end{abstract}

\section{Introduction}

With the expansion use of electric device, including personal computers, mobile phones, microwave oven, and other military equipment and/or space equipment, microwave has become a new pollution to our health [1-6]. The effective way to solve this problem is the development of new microwave absorption materials $[7,8]$. The basic requirement of the microwave absorption materials is to show strong microwave absorption, represented by reflection loss [9]. Usually, the microwave absorption materials are to dissipate the incident microwave which includes the dielectric dissipation and magnetic dissipation [10, 11]. Excellent microwave absorption materials also exhibit compatibility between the dielectric dissipation and magnetic dissipation. The magnetic dissipation can be easily achieved by using magnetic materials such as magnetic iron oxide. As a result, magnetite is mostly utilized as microwave absorption materials $[12,13]$. The dielectric dissipation can be achieved by introducing the dielectric materials and/or conducting materials [14, 15]. These include phthalocyanine copper and its derivatives
[16], the carbon materials including CNT [17], carbon black, and graphene [18], and the conducting polymers such as polyaniline and polythiophene [19]. The conducting polymers that usually combine the low density and excellent conductivity have attracted considerable attention both from the research and the practical application. In the conducting polymers, polyaniline (PAN) can be easily obtained and shows excellent conductivity after doping. Up to now, PAN has been used to prepare composites with polyethylene, poly(vinylidene fluoride), graphene, CNT, and others $[20,21]$.

With the magnetite as the magnetic dissipation part and PAN as the dielectric dissipation part, PAN and magnetite hybrid materials can be obtained to be used as microwave absorption materials. However, another problem is the compatibility between them due to the inorganic part of magnetite and organic part of PAN. To solve this problem, core-shell-structured hybrid containing magnetite core and PAN shell can be imagined.

In this study, we fabricated hybrid PAN@ $@ \mathrm{Fe}_{3} \mathrm{O}_{4}$ by the in situ aniline polymerization at the spherical of $\mathrm{Fe}_{3} \mathrm{O}_{4}$ which is 
prepared by the solvothermal process. The $\mathrm{PAN} @ \mathrm{Fe}_{3} \mathrm{O}_{4}$ hybrids are characterized by XPS, XRD, TGA, SEM, TEM, FTIR, and VSM. After that, microwave absorption property of the prepared PAN@ $\mathrm{Fe}_{3} \mathrm{O}_{4}$ hybrids is studied in detail.

\section{Experimental Section}

2.1. Materials. Ethylene glycol (99\%), $\mathrm{FeCl}_{3} \cdot 6 \mathrm{H}_{2} \mathrm{O}$ (99\%), and polyethylene glycol 2000 (99\%) were purchased from Kelong Reagents, Chengdu, China. Sodium dodecyl benzene sulfonate (SDBS, 99\%), hydrochloric acid (37\%), ammonium sulfate (98\%), and aniline (99\%) were purchased from Changzheng Reagents, Chengdu, China. Other chemicals and reagents were commercial available products, and all of them were used as received.

2.2. Preparation of $\mathrm{Fe}_{3} \mathrm{O}_{4}$. Magnetite was fabricated by the solvothermal process throughout previous literature [8]. $\mathrm{FeCl}_{3} \cdot 6 \mathrm{H}_{2} \mathrm{O}(10.0 \mathrm{~g})$ and polyethylene glycol $2000(3.7 \mathrm{~g})$ were mixed with $160 \mathrm{ml}$ ethylene glycol at RT, followed by adding sodium acetate trihydrate $(27.0 \mathrm{~g})$. The system was mixed by mechanical agitation as well as ultrasonication for $40 \mathrm{~min}$ to form an orange solution. After that, the aboveprepared mixture was poured into an autoclave; the whole system was heated at $180^{\circ} \mathrm{C}$ for $12 \mathrm{~h}$, after that it was cooled down to RT. The product was segregated by a magnet and was purified 3-5 times with purified water and ethanol, respectively. Finally, the product was dried under vacuum at $70^{\circ} \mathrm{C}$ for $8 \mathrm{~h}$.

2.3. Preparation of Polyaniline and $\mathrm{Fe}_{3} \mathrm{O}_{4}\left(\mathrm{PAN@Fe} \mathrm{O}_{4}\right)$ Hybrids. The polyaniline and $\mathrm{Fe}_{3} \mathrm{O}_{4}$ (PAN@Fe $\mathrm{P}_{4}$ ) hybrids were fabricated by the in situ aniline polymerization at the spherical of $\mathrm{Fe}_{3} \mathrm{O}_{4}$ with the existence of ammonium sulfate. With the change of the amount of the aniline and ammonium sulfate, polyaniline and $\mathrm{Fe}_{3} \mathrm{O}_{4}$ hybrids with different contents of polyaniline were obtained. The typical procedure is as follows: $0.25 \mathrm{~g} \mathrm{Fe}_{3} \mathrm{O}_{4}$ was dispersed in $100 \mathrm{ml}$ deionized water with the help of SDBS (25 mg) and mechanical agitation. After that, the system was cooled at $0-5^{\circ} \mathrm{C}$ through the ice. At the time, aniline $(0.25 \mathrm{ml})$, dissolved in $0.1 \mathrm{~mol} / \mathrm{l} \mathrm{HCl}$ $(50 \mathrm{ml})$, was also cooled at $0-5^{\circ} \mathrm{C}$ through another ice system. The cooled aniline solution was mixed with the $\mathrm{Fe}_{3} \mathrm{O}_{4}$ dispersion with vigorous mechanical agitation in the ice bath. The ammonium sulfate $(2.5 \mathrm{~g})$ was dissolved in $25 \mathrm{ml}$ purified water at $0-5^{\circ} \mathrm{C}$ in the third ice bath. After being cooled down, the ammonium sulfate was put dropwise in $\mathrm{Fe}_{3} \mathrm{O}_{4}$ and aniline mixture. The polymerization was kept on for at least $12 \mathrm{~h}$. In this study, three polyaniline and $\mathrm{Fe}_{3} \mathrm{O}_{4}$ hybrids named as PAN@Fe $\mathrm{O}_{4}-1, \mathrm{PAN}_{3} @ \mathrm{Fe}_{3} \mathrm{O}_{4}-2$, and $\mathrm{PAN} @ \mathrm{Fe}_{3} \mathrm{O}_{4^{-}}$ 3 were prepared.

2.4. Characterization. The structure of PAN@Fe ${ }_{3} \mathrm{O}_{4}$ hybrid materials was characterized by XRD (Rigaku RINT 2400) and XPS (PHI-5300 ESCA). FTIR (8000S) was also utilized to characterize the PAN@ $\mathrm{Fe}_{3} \mathrm{O}_{4}$ hybrids. The content of polyaniline in the PAN@ $\mathrm{Fe}_{3} \mathrm{O}_{4}$ hybrid was calculated by TGA (Q50). The morphologies of PAN@Fe $\mathrm{O}_{4}$ hybrids were studied by SEM (JSM-6490LV) and TEM (H600). The magnetic property of PAN@Fe $\mathrm{O}_{4}$ hybrids was studied by VSM

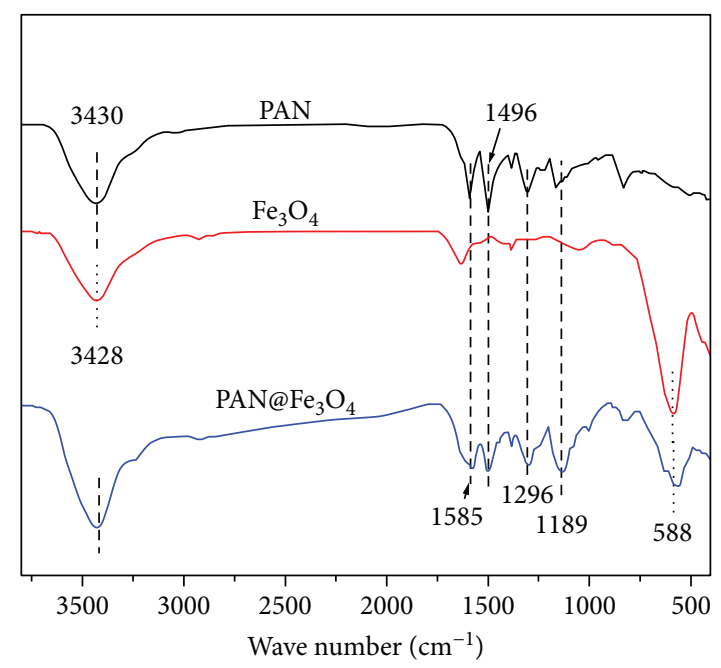

Figure 1: FTIR spectrum of PAN, $\mathrm{Fe}_{3} \mathrm{O}_{4}$, and PAN@Fe $\mathrm{O}_{4}-1$.

(BHV-525). The electromagnetic property of PAN@Fe $\mathrm{O}_{4}$ hybrids was tested on a vector network analyzer (8720ET) at $0.5-18 \mathrm{GHz}$. The sample was fabricated through blending $\mathrm{PAN} @ \mathrm{Fe}_{3} \mathrm{O}_{4}$ hybrids with wax in a mass ratio of $3: 1$.

\section{Results and Discussion}

In the study, polyaniline and $\mathrm{Fe}_{3} \mathrm{O}_{4}\left(\mathrm{PAN} @ \mathrm{Fe}_{3} \mathrm{O}_{4}\right.$ ) hybrids are fabricated and their microwave absorption property is studied. The PAN@Fe $\mathrm{O}_{4}$ hybrid is fabricated by the in situ aniline polymerization at the spherical of $\mathrm{Fe}_{3} \mathrm{O}_{4}$ which is prepared by the solvothermal process [8]. Figure 1 shows FTIR spectra of $\mathrm{PAN}, \mathrm{Fe}_{3} \mathrm{O}_{4}$, as well as $\mathrm{PAN} @ \mathrm{Fe}_{3} \mathrm{O}_{4}-1$; compared with that of $\mathrm{Fe}_{3} \mathrm{O}_{4}$, the FTIR curves of PAN@Fe $\mathrm{O}_{4}-1$ show additional absorption peaks at $3430 \mathrm{~cm}^{-1}(\mathrm{~N}-\mathrm{H}), 1585$ and $1496 \mathrm{~cm}^{-1}$ (benzene ring), and $1189 \mathrm{~cm}^{-1}$ (AR-N) which indicate the existence of polyaniline in the system [19]. In addition, the peak at $588 \mathrm{~cm}^{-1}(\mathrm{Fe}-\mathrm{O})$ is observed on the spectra curves of $\mathrm{Fe}_{3} \mathrm{O}_{4}$ and $\mathrm{PAN} @ \mathrm{Fe}_{3} \mathrm{O}_{4}-1$.

XPS is also used to characterize the composition of the obtained PAN@ $\mathrm{Fe}_{3} \mathrm{O}_{4}$ hybrids. Figure 2(a) shows the XPS spectra of $\mathrm{Fe}_{3} \mathrm{O}_{4}$ and $\mathrm{PAN} @ \mathrm{Fe}_{3} \mathrm{O}_{4}-1$. On the spectrum of $\mathrm{Fe}_{3} \mathrm{O}_{4}$, the peaks at $534 \mathrm{eV}$ and $716 \mathrm{eV}$ correspond the $\mathrm{O} 1 \mathrm{~s}$ and Fe2p, while the peak at $287 \mathrm{eV}$ is resulted from the C1s which might come from the ethylene glycol and polyethylene glycol 2000 used during the solvothermal process. The Fe2p peak can be divided into two peaks at $711 \mathrm{eV}$ and $725 \mathrm{eV}$ which come from Fe2p1/2 and Fe2p3/2 as shown in Figure 2(b); this confirms the existence of $\mathrm{Fe}_{3} \mathrm{O}_{4}$. In comparison, the XPS spectrum of PAN@ $\mathrm{Fe}_{3} \mathrm{O}_{4}-1$ shows new peak at $405 \mathrm{eV}$ which is attributed to the N1s from the polyaniline at the spherical of PAN@ $\mathrm{Fe}_{3} \mathrm{O}_{4}-1$. Both of the FTIR and the XPS confirm the preparation of polyaniline and $\mathrm{Fe}_{3} \mathrm{O}_{4}$ hybrids [7].

$\mathrm{XRD}$ is a technic to confirm component of prepared new nanocomposites by comparing XRD pattern peaks with the standard card. Figure 3 shows XRD curves of prepared samples. As shown in the picture, six peaks at $30^{\circ}, 35^{\circ}, 43^{\circ}, 54^{\circ}$, $57^{\circ}$, and $63^{\circ}$ which match well with (220), (311), (400), 


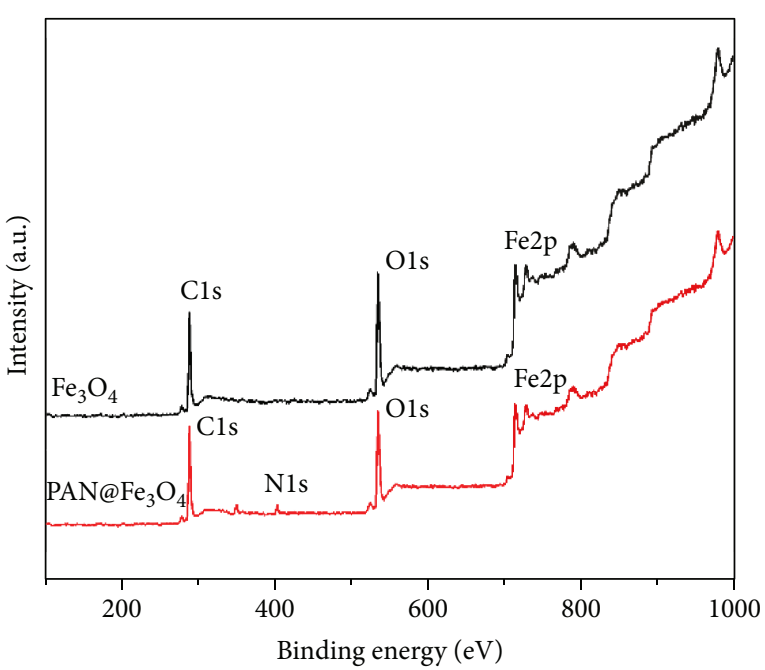

(a)

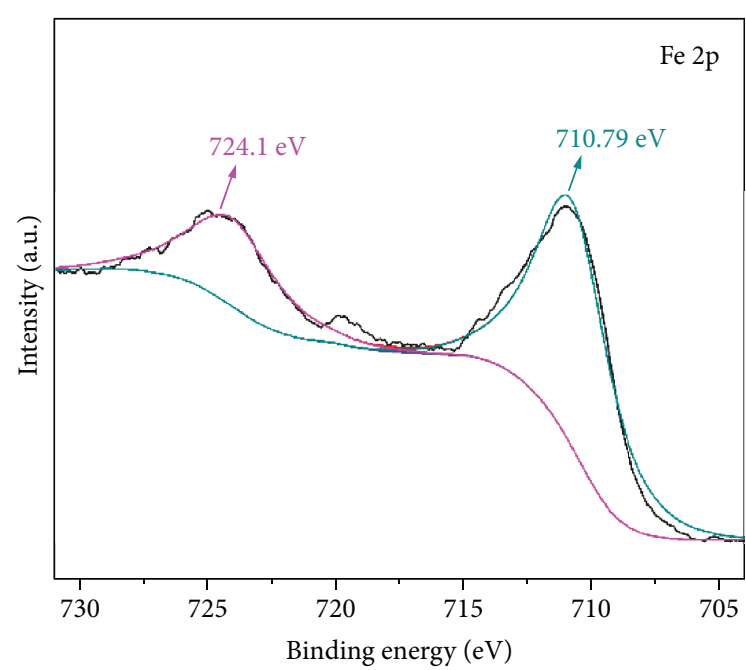

(b)

FIgURE 2: XPS spectra of $\mathrm{Fe}_{3} \mathrm{O}_{4}$ and PAN@Fe $\mathrm{O}_{4}-1$ (a) and Fe2p peak (b).

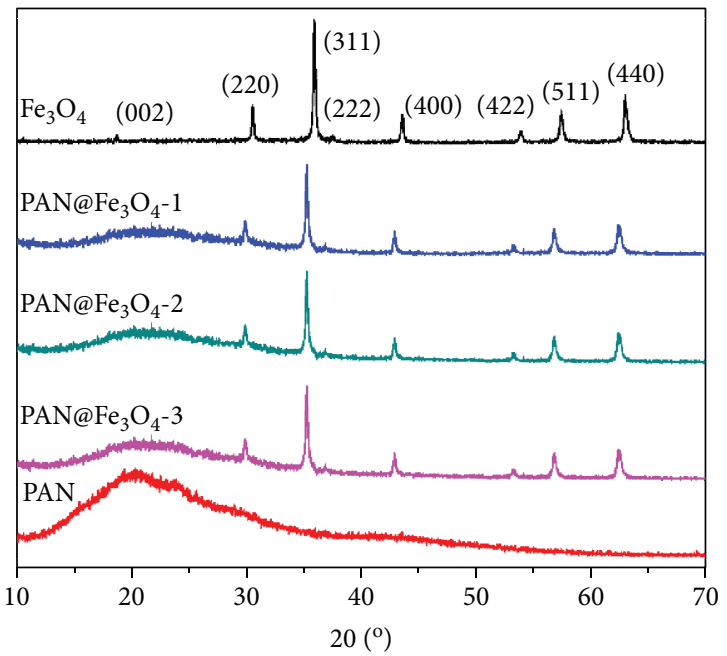

Figure 3: XRD pattern of $\mathrm{Fe}_{3} \mathrm{O}_{4}, \mathrm{PAN} @ \mathrm{Fe}_{3} \mathrm{O}_{4}-1, \mathrm{PAN} @ \mathrm{Fe}_{3} \mathrm{O}_{4}-2$, $\mathrm{PAN} @ \mathrm{Fe}_{3} \mathrm{O}_{4}-3$, and PAN.

(422), (511), and (440) planes of the standard XRD of magnetite (JCPDS file no.19-0629) are observed on the curves of $\mathrm{Fe}_{3} \mathrm{O}_{4}$. While a wide peak at $20^{\circ}$ is seen on the curves of PAN.PAN@Fe $\mathrm{O}_{4}-1$ shows peaks combining from PAN and $\mathrm{Fe}_{3} \mathrm{O}_{4}$, indicating the composition of PAN and $\mathrm{Fe}_{3} \mathrm{O}_{4}$ in PAN@ $\mathrm{Fe}_{3} \mathrm{O}_{4}-1$. The other samples also show similar XRD patterns which confirm the $\mathrm{Fe}_{3} \mathrm{O}_{4}$ in the PAN@ $\mathrm{Fe}_{3} \mathrm{O}_{4}$ hybrids [22].

After the characterization of the composition of PAN@$\mathrm{Fe}_{3} \mathrm{O}_{4}$ hybrids, the micro morphology of them is studied through SEM and TEM. Figure 4 shows SEM micro images of $\mathrm{Fe}_{3} \mathrm{O}_{4}$ and $\mathrm{PAN} @ \mathrm{Fe}_{3} \mathrm{O}_{4}-1$. As shown in the figure, the $\mathrm{Fe}_{3} \mathrm{O}_{4}$ exhibits smooth surface. In addition, anomalous nanoparticles including spheres, hemispheres, bowls, and open balls are observed for $\mathrm{Fe}_{3} \mathrm{O}_{4}$. While for PAN@Fe $\mathrm{O}_{4}{ }^{-}$ 1 , its surface becomes coarser indicating the existence of the polyaniline. More importantly, the shape of the PAN@$\mathrm{Fe}_{3} \mathrm{O}_{4}-1$ becomes regular spheres. The structure change of the PAN@Fe $\mathrm{O}_{4}-1$ from $\mathrm{Fe}_{3} \mathrm{O}_{4}$ indicates the formation of the core-shell-structured particles.

Figure 5 shows the TEM micro images of $\mathrm{Fe}_{3} \mathrm{O}_{4}$ and PAN@Fe $\mathrm{O}_{4}$-1. Similar to that of the SEM micro image, the TEM micro image of $\mathrm{Fe}_{3} \mathrm{O}_{4}$ shows irregular shapes of nanoparticles. In addition, it is clearly that $\mathrm{Fe}_{3} \mathrm{O}_{4}$ shows hollow structure. As for that of $\mathrm{PAN} @ \mathrm{Fe}_{3} \mathrm{O}_{4}-1$, a shell can be observed at the spherical of the nanoparticles. What is more, it seems that the hollow structure of the $\mathrm{Fe}_{3} \mathrm{O}_{4}$ is filled with something after the polymerization of aniline. Both of the SEM and TEM results indicate the core-shell structure of PAN@Fe ${ }_{3} \mathrm{O}_{4}-1$.

After the confirmation of the fabrication of PAN@Fe ${ }_{3} \mathrm{O}_{4}$ hybrids, the content of polyaniline in the $\mathrm{PAN} @ \mathrm{Fe}_{3} \mathrm{O}_{4}$ hybrids is calculated by the TGA measurement. Figure 6 shows the TGA curves of $\mathrm{Fe}_{3} \mathrm{O}_{4}, \mathrm{PAN} @ \mathrm{Fe}_{3} \mathrm{O}_{4}-1, \mathrm{PAN} @-$ $\mathrm{Fe}_{3} \mathrm{O}_{4}$-2, and PAN@ $\mathrm{Fe}_{3} \mathrm{O}_{4}-3$. $\mathrm{Fe}_{3} \mathrm{O}_{4}$ shows only $2 \%$ weight decrement when the temperature is up to $600^{\circ} \mathrm{C}$, which is negligible. As for the PAN@ $\mathrm{Fe}_{3} \mathrm{O}_{4}$ hybrids, obvious weight decrement resulting from the decomposing of polyaniline is observed. The residual mass of PAN@Fe $\mathrm{O}_{4}-1, \mathrm{PAN} @-$ $\mathrm{Fe}_{3} \mathrm{O}_{4}-2$, and $\mathrm{PAN} @ \mathrm{Fe}_{3} \mathrm{O}_{4}-3$ is $90 \%, 84 \%$, and $77 \%$, respectively. The TGA results mean that the content of polyaniline in PAN@ $\mathrm{Fe}_{3} \mathrm{O}_{4}-1, \mathrm{PAN} @ \mathrm{Fe}_{3} \mathrm{O}_{4}-2$, and PAN@$\mathrm{Fe}_{3} \mathrm{O}_{4}-3$ is $10 \mathrm{wt} \%, 16 \mathrm{wt} \%$, and $23 \mathrm{wt} \%$, respectively.

The magnetic property of $\mathrm{PAN} @ \mathrm{Fe}_{3} \mathrm{O}_{4}$ hybrid composite was studied by a VSM. Figure 7 shows the saturation magnetization of the samples indicating the magnetic property of the PAN@ $\mathrm{Fe}_{3} \mathrm{O}_{4}$ hybrids. According to the results, the saturation magnetization decreases with the increasing content of polyaniline due to the decrement of content of $\mathrm{Fe}_{3} \mathrm{O}_{4}$ which contributes the magnetic properties effectively. The saturation magnetization of PAN@$\mathrm{Fe}_{3} \mathrm{O}_{4}-1, \mathrm{PAN} @ \mathrm{Fe}_{3} \mathrm{O}_{4}-2$, and $\mathrm{PAN} @ \mathrm{Fe}_{3} \mathrm{O}_{4}-3$ is 75.3, 58.9, and $42.1 \mathrm{emu} / \mathrm{g}$, respectively.

With the fabrication and characterization of PAN@$\mathrm{Fe}_{3} \mathrm{O}_{4}$ hybrids, their microwave absorption property is studied. Permittivity $\left(\varepsilon=\varepsilon^{\prime}+i \varepsilon^{\prime \prime}\right)$ as well as permeability 


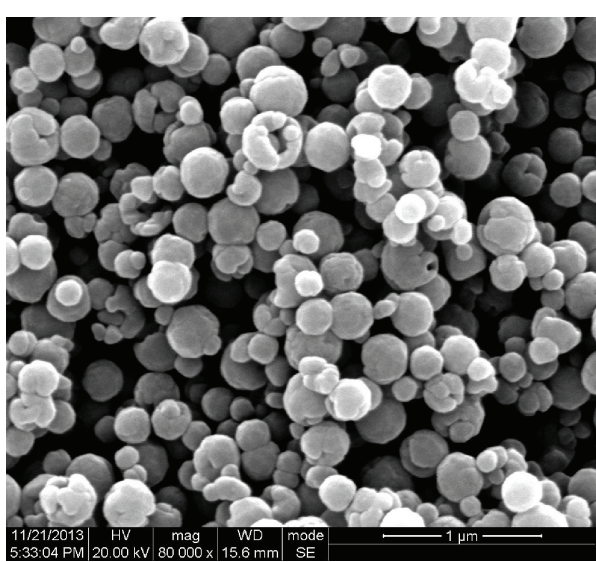

(a)

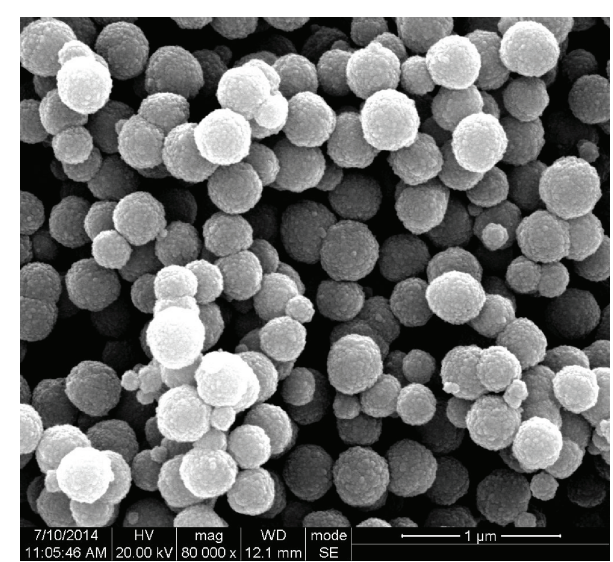

(b)

Figure 4: SEM micro images of $\mathrm{Fe}_{3} \mathrm{O}_{4}$ and PAN@ $\mathrm{Fe}_{3} \mathrm{O}_{4}-1$.

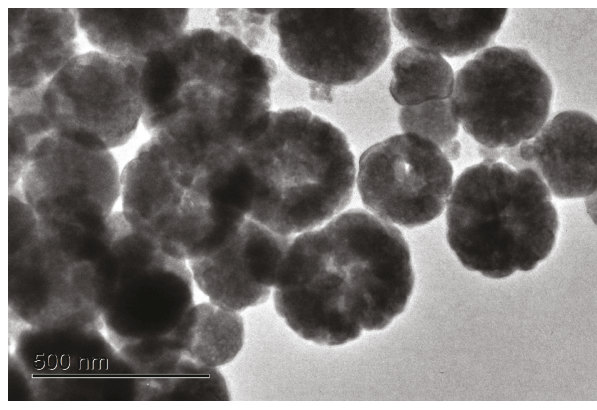

(a)

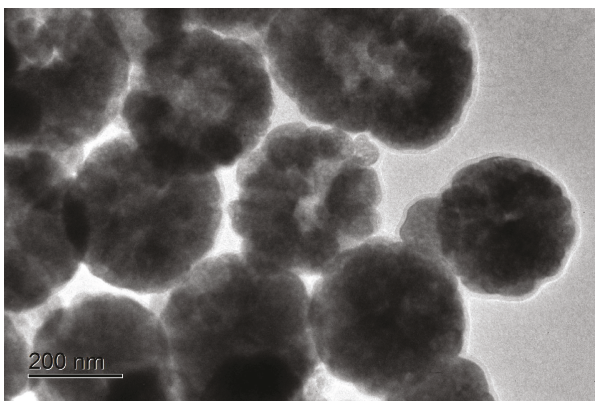

(b)

Figure 5: TEM micro images of $\mathrm{Fe}_{3} \mathrm{O}_{4}$ and PAN@Fe $\mathrm{O}_{4}-1$.

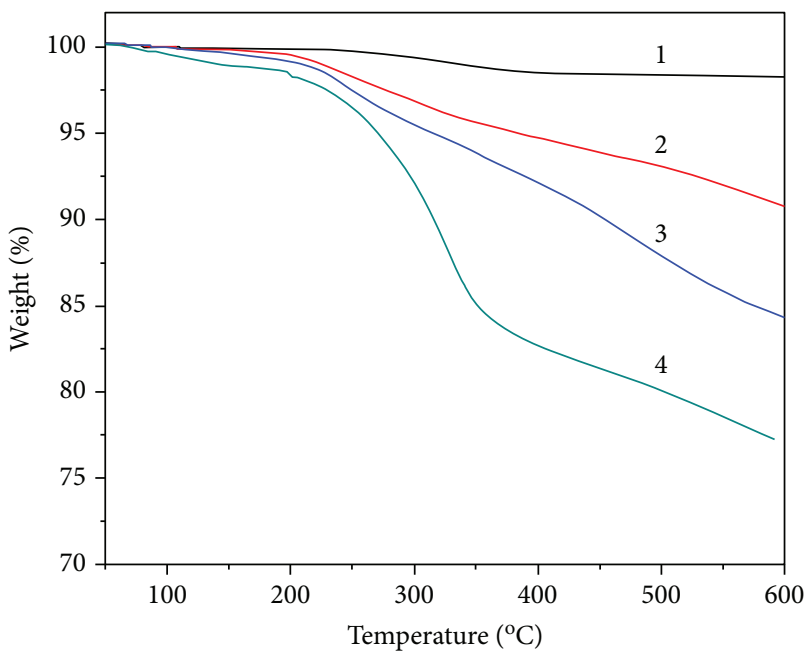

Figure 6: TGA curves of $\mathrm{Fe}_{3} \mathrm{O}_{4}$ (curve 1), PAN@ $\mathrm{Fe}_{3} \mathrm{O}_{4}-1$ (curve 2), $\mathrm{PAN} @ \mathrm{Fe}_{3} \mathrm{O}_{4}-2$ (curve 3), and $\mathrm{PAN} @ \mathrm{Fe}_{3} \mathrm{O}_{4}-3$ (curve 4).

$\left(\mu=\mu^{\prime}+j \mu^{\prime \prime}\right)$ were measured from $0.5-18 \mathrm{GHz}$ for $\mathrm{Fe}_{3} \mathrm{O}_{4}$ and PAN@ $\mathrm{Fe}_{3} \mathrm{O}_{4}$ hybrids. By using the obtained permittivity and permeability, $\mathrm{PAN} @ \mathrm{Fe}_{3} \mathrm{O}_{4}$ hybrids' microwave absorption properties are calculated by using transmit line theory $[23,24]$. Figure 8(a) exhibits reflection loss (RL) of $\mathrm{Fe}_{3} \mathrm{O}_{4}$; the minimum $\mathrm{RL}$ is $-15.3,-12.7,-15.5$, and $-17.2 \mathrm{~dB}$ at $1.0,1.5,2.0$, and $2.5 \mathrm{~mm}$, respectively. Usually, the reflection

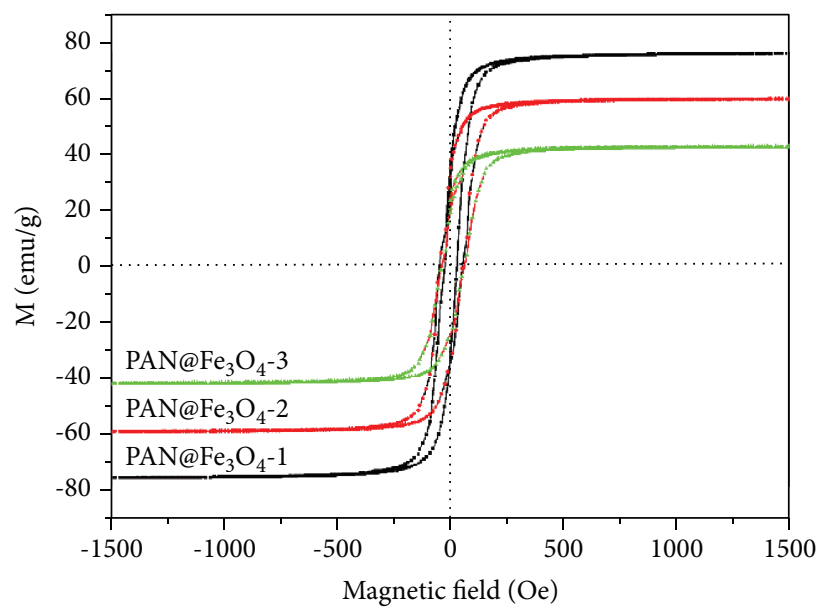

FIgURE 7: Magnetization curves of PAN@Fe $\mathrm{O}_{4}-1$, PAN@Fe $\mathrm{O}_{4}-2$, and PAN@Fe $\mathrm{O}_{4}-3$.

loss below $-10 \mathrm{~dB}$ indicates that $90 \%$ microwave energy is dissipated and the reflection loss below $-20 \mathrm{~dB}$ means that 99\% microwave energy is being dissipated. As the minimum reflection loss of $\mathrm{Fe}_{3} \mathrm{O}_{4}$ is higher than $-20 \mathrm{~dB}$, it is not good enough to be used directly.

Figures 8(b) and 8(c) show the RL of PAN@ $\mathrm{Fe}_{3} \mathrm{O}_{4}-1$ and PAN@ $\mathrm{Fe}_{3} \mathrm{O}_{4}-2$. The outcome shows both RL of PAN@$\mathrm{Fe}_{3} \mathrm{O}_{4}-1$ and PAN@Fe $\mathrm{O}_{4}-2$ are worse than that of $\mathrm{Fe}_{3} \mathrm{O}_{4}$, 


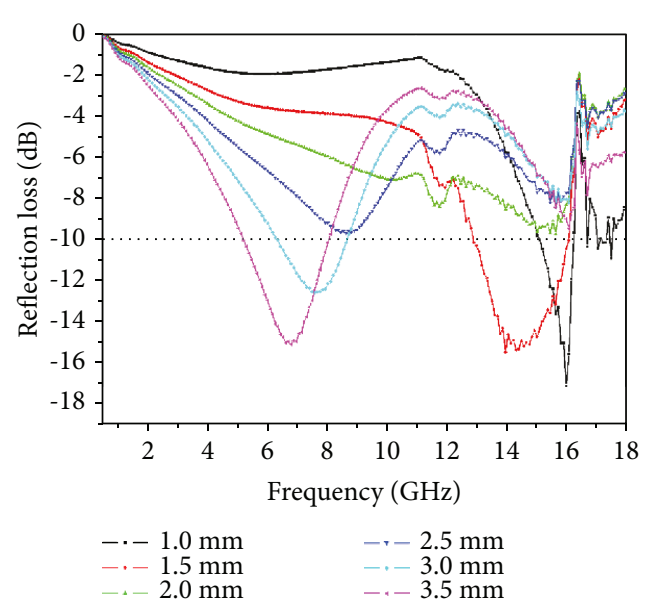

(a)

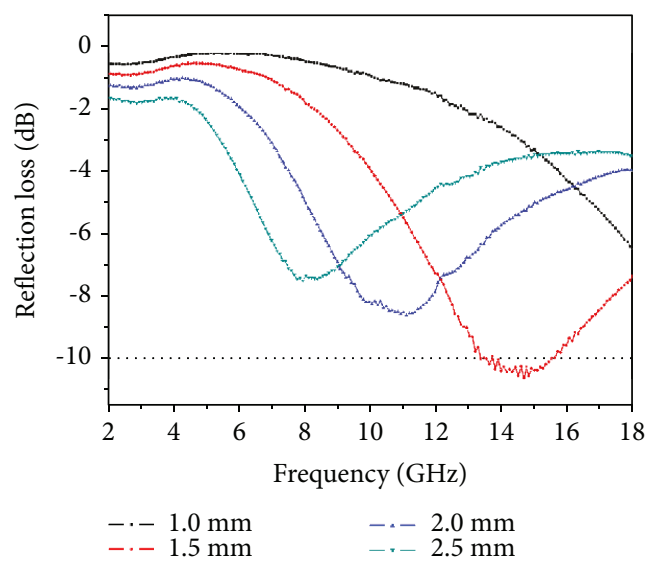

(c)

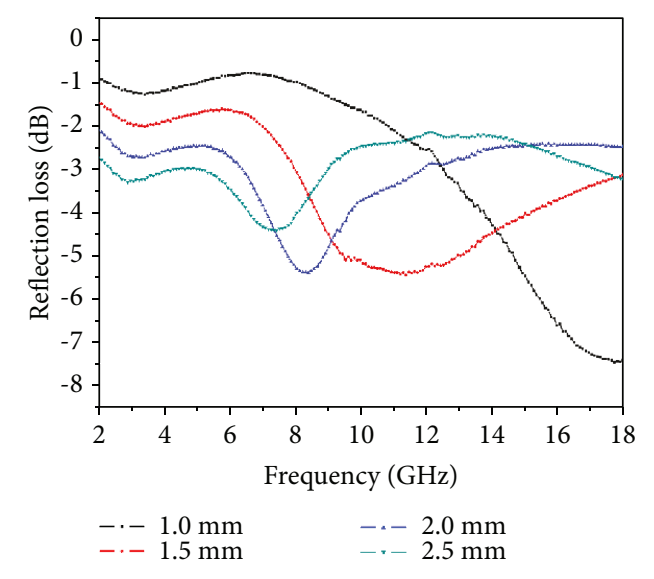

(b)

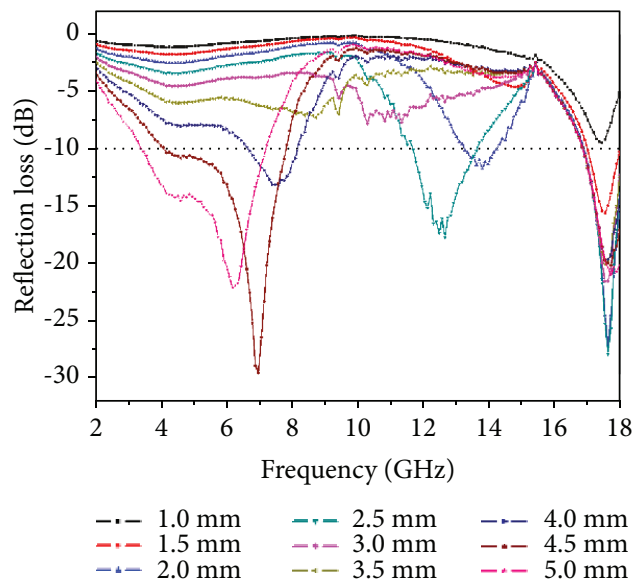

(d)

Figure 8: Reflection loss of $\mathrm{Fe}_{3} \mathrm{O}_{4}$ (a), PAN@Fe $\mathrm{O}_{4}-1$ (b), PAN@ $\mathrm{Fe}_{3} \mathrm{O}_{4}-2$ (c), and PAN@Fe $\mathrm{O}_{4}-3$ (d).

which might be contributed to the mismatching of impedance between $\mathrm{Fe}_{3} \mathrm{O}_{4}$ and polyaniline. While for PAN@$\mathrm{Fe}_{3} \mathrm{O}_{4}-3$, excellent microwave absorption property is obtained. As can be seen through Figure 8(d), the minimum RL of PAN@ $\mathrm{Fe}_{3} \mathrm{O}_{4}-3$ is as low as $-29.3 \mathrm{~dB}$. The low reflection loss of PAN@Fe $\mathrm{O}_{4}-3$ is due to the changeable content of polyaniline through the aniline polymerization at the spherical of $\mathrm{Fe}_{3} \mathrm{O}_{4}$. As a result, controlling the in situ aniline polymerization at the spherical of $\mathrm{Fe}_{3} \mathrm{O}_{4}$ can adjust the microwave absorption property of the obtained PAN@$\mathrm{Fe}_{3} \mathrm{O}_{4}$ hybrids.

\section{Conclusions}

In conclusion, a series of polyaniline and $\mathrm{Fe}_{3} \mathrm{O}_{4}$ (PAN@$\mathrm{Fe}_{3} \mathrm{O}_{4}$ ) hybrids was prepared to study their microwave absorption properties. PAN@ $\mathrm{Fe}_{3} \mathrm{O}_{4}$ was fabricated by the in situ aniline polymerization at the spherical of $\mathrm{Fe}_{3} \mathrm{O}_{4}$. FTIR, XPS, and XRD measurements showed the composition of polyaniline and $\mathrm{Fe}_{3} \mathrm{O}_{4}$ in the prepared $\mathrm{PAN} @ \mathrm{Fe}_{3} \mathrm{O}_{4}$ hybrids. SEM and TEM micro images indicated the coreshell structure of the PAN@ $\mathrm{Fe}_{3} \mathrm{O}_{4}$ hybrids. The TGA results suggested that the content of polyaniline in $\mathrm{PAN} @ \mathrm{Fe}_{3} \mathrm{O}_{4}-1$, PAN@ $\mathrm{Fe}_{3} \mathrm{O}_{4}-2$, and PAN@ $\mathrm{Fe}_{3} \mathrm{O}_{4}-3$ is $10 \mathrm{wt} \%, 16 \mathrm{wt} \%$, and
$23 \mathrm{wt} \%$, respectively. The saturation magnetization of the PAN@Fe $\mathrm{O}_{3}$ decreased with the increment of PAN content in the hybrids. The minimum reflection loss of PAN@$\mathrm{Fe}_{3} \mathrm{O}_{4}-3$ was as low as $-29.3 \mathrm{~dB}$ which is much better than the other samples. Controlling the in situ aniline polymerization at the spherical of $\mathrm{Fe}_{3} \mathrm{O}_{4}$ can adjust the microwave absorption of the obtained PAN@ $\mathrm{Fe}_{3} \mathrm{O}_{4}$ hybrids.

\section{Data Availability}

The data used to support the findings of this study are included within the article. The funding statement will be provided in the coming revised version.

\section{Conflicts of Interest}

The authors declare that there are no conflicts of interest regarding the publication of this paper.

\section{Acknowledgments}

The financial support from the National Natural Science Foundation of China (20176169) is gratefully acknowledged. 


\section{References}

[1] M. Choi, D. Choi, and J. Kim, "Magnetic permeability behaviors of FeCo micro hollow fiber composites," Electronic Materials Letters, vol. 11, no. 5, pp. 782-787, 2015.

[2] L. B. Kong, Z. W. Li, L. Liu et al., "Recent progress in some composite materials and structures for specific electromagnetic applications," International Materials Reviews, vol. 58, no. 4, pp. 203-259, 2013.

[3] T. Liu, Y. Pang, M. Zhu, and S. Kobayashi, "Microporous Co@ $\mathrm{CoO}$ nanoparticles with superior microwave absorption properties," Nanoscale, vol. 6, no. 4, pp. 2447-2454, 2014.

[4] Y. Zhang, Y. Huang, T. Zhang et al., "Broadband and tunable high-performance microwave absorption of an ultralight and highly compressible graphene foam," Advanced Materials, vol. 27, no. 12, pp. 2049-2053, 2015.

[5] H. Wu, G. Wu, Y. Ren, L. Yang, L. Wang, and X. Li, " $\mathrm{Co}^{2+}$, $\mathrm{Co}^{3+}$ ratio dependence of electromagnetic wave absorption in hierarchical $\mathrm{NiCo}_{2} \mathrm{O}_{4}-\mathrm{CoNiO}_{2}$ hybrids," Journal of Materials Chemistry C, vol. 3, no. 29, pp. 7677-7690, 2015.

[6] H.-B. Zhang, Q. Yan, W. G. Zheng, Z. He, and Z. Z. Yu, "Tough graphene-polymer microcellular foams for electromagnetic interference shielding," ACS Applied Materials \& Interfaces, vol. 3, no. 3, pp. 918-924, 2011.

[7] L. Yan, Z. Pu, M. Xu, R. Wei, and X. Liu, "Fabrication and electromagnetic properties of conjugated $\mathrm{NH}_{2}-\mathrm{CuPc} @ \mathrm{Fe}_{3} \mathrm{O}_{4}$," Journal of Electronic Materials, vol. 46, no. 10, pp. 56085618, 2017.

[8] R. Wei, J. Wang, Z. Wang, L. Tong, and X. Liu, "Magnetitebridged carbon nanotubes/graphene sheets three-dimensional network with excellent microwave absorption," Journal of Electronic Materials, vol. 46, no. 4, pp. 2097-2105, 2017.

[9] G. Sun, B. Dong, M. Cao, B. Wei, and C. Hu, "Hierarchical dendrite-like magnetic materials of $\mathrm{Fe}_{3} \mathrm{O}_{4}, \gamma-\mathrm{Fe}_{2} \mathrm{O}_{3}$, and $\mathrm{Fe}$ with high performance of microwave absorption," Chemistry of Materials, vol. 23, no. 6, pp. 1587-1593, 2011.

[10] Y. Zhan, X. Yang, F. Meng, J. Wei, R. Zhao, and X. Liu, "Controllable synthesis, magnetism and solubility enhancement of graphene nanosheets/magnetite hybrid material by covalent bonding," Journal of Colloid and Interface Science, vol. 363, no. 1, pp. 98-104, 2011.

[11] D. C. Marcano, D. V. Kosynkin, J. M. Berlin et al., "Improved synthesis of graphene oxide," ACS Nano, vol. 4, no. 8, pp. 4806-4814, 2010.

[12] Y. Zhan, R. Zhao, F. Meng et al., "Oriented growth of magnetite along the carbon nanotubes via covalently bonded method in a simple solvothermal system," Materials Science and Engineering: $B$, vol. 176, no. 10, pp. 779-784, 2011.

[13] R. Zhao, K. Jia, J. J. Wei, J. X. Pu, and X. B. Liu, "Hierarchically nanostructured $\mathrm{Fe}_{3} \mathrm{O}_{4}$ microspheres and their novel microwave electromagnetic properties," Materials Letters, vol. 64, no. 3, pp. 457-459, 2010.

[14] Y. N. Hao, X. H. Wang, S. O'Brien, J. Lombardi, and L. T. Li, "Flexible $\mathrm{BaTiO}_{3} / \mathrm{PVDF}$ gradated multilayer nanocomposite film with enhanced dielectric strength and high energy density," Journal of Materials Chemistry C, vol. 3, no. 37, pp. 9740-9747, 2015.

[15] Z. M. Dang, L. Wang, Y. Yin, Q. Zhang, and Q. Q. Lei, "Giant dielectric permittivities in functionalized carbon-nanotube/ electroactive-polymer nanocomposites," Advanced Materials, vol. 19, no. 6, pp. 852-857, 2007.
[16] Z. Wang, R. Wei, and X. Liu, "Dielectric properties of reduced graphene oxide/copper phthalocyanine nanocomposites fabricated through $\pi-\pi$ interaction," Journal of Electronic Materials, vol. 46, no. 1, pp. 488-496, 2017.

[17] F. Jin, M. Feng, K. Jia, and X. Liu, “Aminophenoxyphthalonitrile modified MWCNTs/polyarylene ether nitriles composite films with excellent mechanical, thermal, dielectric properties," Journal of Materials Science: Materials in Electronics, vol. 26, no. 7, pp. 5152-5160, 2015.

[18] R. Wei, J. Wang, H. Zhang, W. Han, and X. Liu, "Crosslinked polyarylene ether nitrile interpenetrating with zinc ion bridged graphene sheet and carbon nanotube network," Polymer, vol. 9, no. 12, p. 342, 2017.

[19] R. Wei, K. Li, J. Ma, H. Zhang, and X. Liu, "Improving dielectric properties of polyarylene ether nitrile with conducting polyaniline," Journal of Materials Science: Materials in Electronics, vol. 27, no. 9, pp. 9565-9571, 2016.

[20] G. K. Elyashevich, L. Terlemezyan, I. S. Kuryndin et al., "Thermochemical and deformational stability of microporous polyethylene films with polyaniline layer," Thermochimica Acta, vol. 374, no. 1, pp. 23-30, 2001.

[21] S. Yu, F. Qin, and G. Wang, "Improving the dielectric properties of poly (vinylidene fluoride) composites by using poly (vinyl pyrrolidone)-encapsulated polyaniline nanorods," Journal of Materials Chemistry C, vol. 4, no. 7, pp. 1504-1510, 2016.

[22] R. Vijayakumar, Y. Koltypin, I. Felner, and A. Gedanken, "Sonochemical synthesis and characterization of pure nanometer-sized $\mathrm{Fe}_{3} \mathrm{O}_{4}$ particles," Materials Science and Engineering: A, vol. 286, no. 1, pp. 101-105, 2000.

[23] S. Sun, Q. He, S. Xiao, Q. Xu, X. Li, and L. Zhou, "Gradientindex meta-surfaces as a bridge linking propagating waves and surface waves," Nature Materials, vol. 11, no. 5, pp. 426431, 2012.

[24] X. Gu, W. Zhu, C. Jia, R. Zhao, W. Schmidt, and Y. Wang, "Synthesis and microwave absorbing properties of highly ordered mesoporous crystalline $\mathrm{NiFe}_{2} \mathrm{O}_{4}$," Chemical Communications, vol. 47, no. 18, pp. 5337-5339, 2011. 


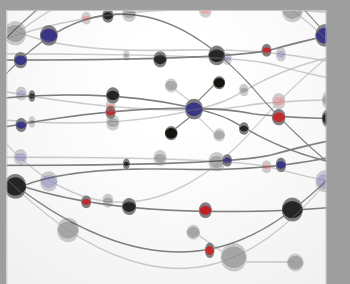

The Scientific World Journal
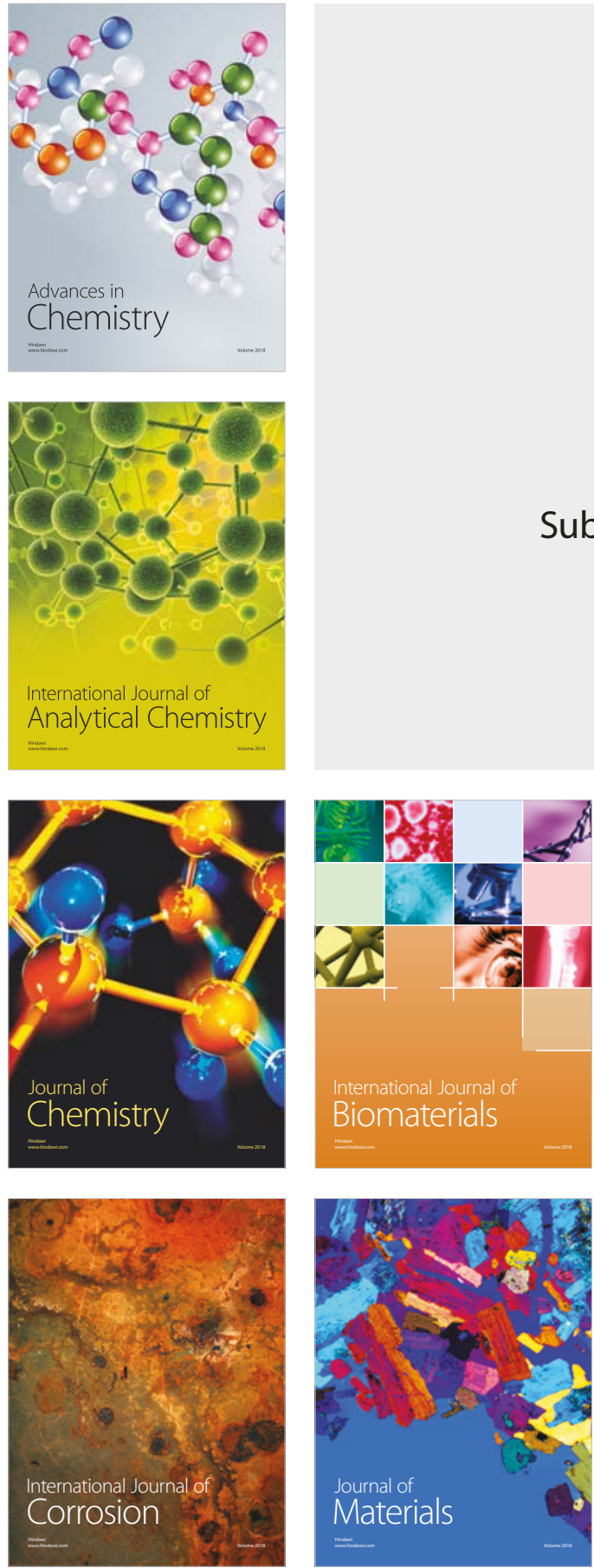

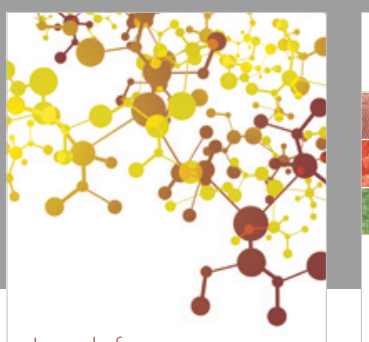

Journal of

Applied Chemistry
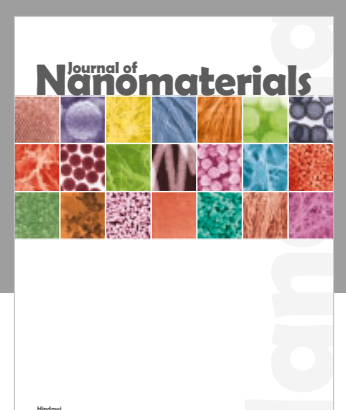

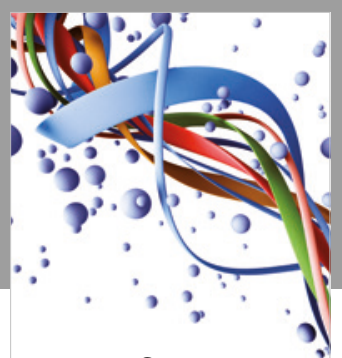

Scientifica

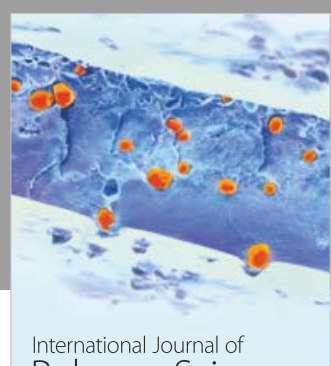

Polymer Science

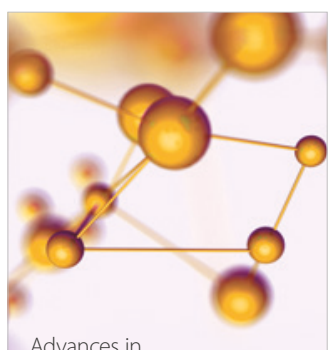

Physical Chemistry
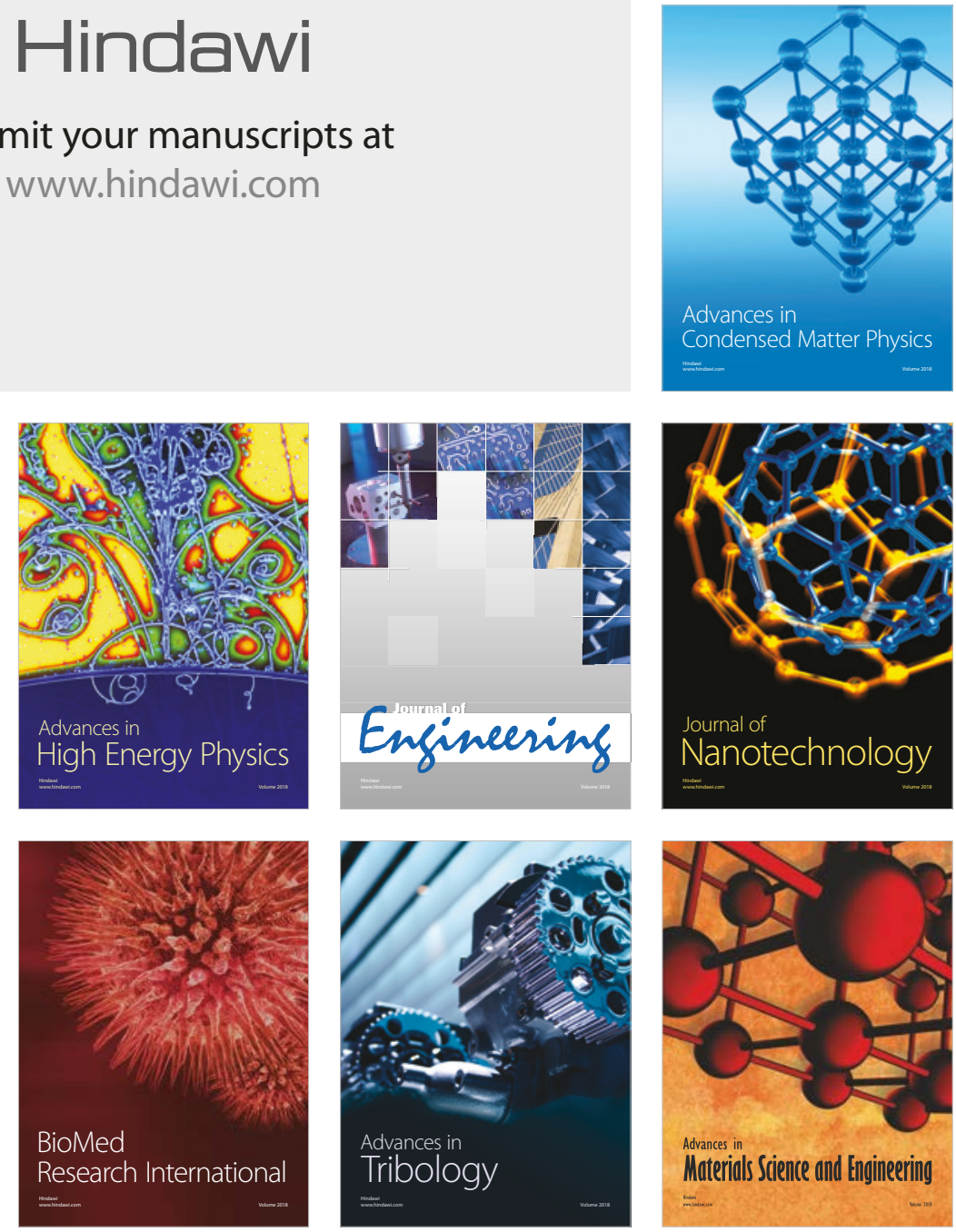